\title{
Reflections on the field of metacognition: issues, challenges, and opportunities
}

\section{Roger Azevedo ${ }^{1}$}

Published online: 3 June 2020

C) Springer Science+Business Media, LLC, part of Springer Nature 2020

There have been major advances in the field of metacognition since I took over as the editorin-chief of the Metacognition and Learning journal in 2011. As the former editor of the journal, I have had the honor and privilege to witness such advances and am proud that this work has been published in the journal. Since the journal's inception by Marcel Veenman, I significantly expanded the editorial board to ensure the journal covered the various multidisciplinary fields that contribute to studying the complex nature of metacognition, enticing interdisciplinary researchers to publish their scientific and innovative work in the journal. After eight years at the helm, I express my gratitude to my Associate Editors (Anastasia Efklides, Jeffrey Greene, and Sabina Kleitman), editorial board members, and editorial assistants (Jason Harley and Michelle Taub) profusely for their invaluable contributions to our journal. I also thank the co-editors of several special issues of the journal for publishing significant work. In this editorial, I reflect on the major issues, challenges, and opportunities that have arisen in the field of metacognition.

\section{Reflections and major issues, challenges and opportunities in the field}

The first article published in the journal, by Veenman, Van Hout-Wolters, and Afflerbach in 2006, described and outlined the most important issues dominating the field fourteen years ago. Looking back, I will reflect on how far we have advanced in addressing each of the issues.

One of the major issues is the abundance of definitions for metacognition found in the journal and other journals in the fields of educational psychology, cognitive psychology, developmental psychology, cognitive science, learning sciences, STEM education, and computational sciences. The plethora of definitions describe various constructs, assumptions, processes, mechanisms, and so forth that impede a unified definition of metacognition. Despite numerous advances in the field, more theoretical work needs to be done for attaining a unified definition of metacognition and its interrelated components (see Dunlosky and Rawson 2019;

Roger Azevedo

roger.azevedo@ucf.edu

1 Department of Learning Sciences \& Educational Research, University of Central Florida, 4000

Central Florida Blvd., Orlando, FL 32816, USA 
Panadero 2017; Schunk and Greene 2018). An excellent example is Norman et al. (2019) review of the major advances in metacognition within different sub-fields of psychology. As researchers and educators across different fields become increasingly interested in studying metacognition based on its relevance toward understanding learning, problem solving, reasoning, conceptual understanding across learners of all ages, topics, domains, tasks, and contexts, the challenge becomes even more pronounced.

In addition to definitional issues, more research is needed to distinguish between metacognitive knowledge from skills. One of the best examples of this distinction is the work of Tarricone (2011) where the most comprehensive conceptual framework of metacognition is provided and clearly distinguishes between metacognitive knowledge and skills. To avoid the common interchangeable use between metacognition and self-regulated learning (SRL) that is found widespread across the various literatures and fields, clear distinctions are imperative for advancing our understanding of metacognition and SRL. As such, it is critical for the future advancement of the field that further research studies the complex relations between Theory of Mind, metamemory, metacognitive awareness, experiences, judgments, evaluations, metacognitive knowledge and skills, decision-making, and reflection. These relations should then be further distinguished based on the self, others, task, context, and so forth. This issue could be partially addressed by integrating several models, frameworks, and theories of metacognition. While several comparisons between models, theories, and frameworks have been published (e.g., Panadero 2017), there has been no significant attempt at integrating them into a unified theory of metacognition. For example, imagine integrating metacognitive knowledge and skills, while also accounting for varying levels of granularity in metacognitive processes that describe the temporal dynamics. We can predict the timing of metacognitive processes and distinguish between the types of metacognitive knowledge (e.g., declarative metacognitive knowledge vs. procedural metacognitive knowledge) and skills (e.g., regulating cognitive strategies), valence associated with metacognitive judgments (e.g., a positive judgment of learning [JOL+] vs. a negative judgment of learning [JOL-]), feedback loops associated with cycles of metacognitive monitoring and control, and so forth across frameworks, models, and theories (e.g., Ackerman and Thompson 2017; Efklides et al. 2018; Hacker and Bol 2019; Koriat 2015; Metcalfe 2009; Nelson and Narens 1990; Winne 2018). However, a unified theory would be incomplete without accounting for emotions, motivation, and social processes depending on the context in which the learner is learning. Can we press forward as researchers by including models of emotions, motivation (e.g., Linnenbrink-Garcia et al. 2016; Renninger and Hidi 2019), and social processes (e.g., Hadwin et al. 2017) into a unified theory of metacognition? How generalizable would this unified theory be to all learners, cultures, learning systems, and contexts (e.g., classroom versus remote instruction)? What adaptations would researchers have to make to account for a myriad of factors and variables, especially related to context? What would be its limitations?

Another notable issue of discussion in the field has been the complex interaction between cognition and metacognition that continues to challenge researchers, as it is hard to distinguish between them since each of the constructs rely and influence each other and share processes (Winne 2018). This represents a dilemma of having a higher-order agent overlooking and governing the cognitive system while also simultaneously being part of it. Advances in the cognitive sciences, computational sciences, robotics, and artificial intelligence (AI) provide excellent tools and techniques for detecting, measuring, and modeling how metacognition and cognition complexly interact with one another. For example, computational modeling holds the key to answering critical questions about the interaction between cognition and 
metacognition by modeling and testing theoretically-based assumptions such as the acquisition and optimal use of metacognitive knowledge and skills in solving complex tasks in AI-based agents including intelligent virtual humans, robots, cyberhumans, etc. (e.g., Kralik et al. 2020). Other relevant research addressing this issue would be the extensive work in the cognitive sciences, embodied cognition, and cognitive neuroscience disciplines, especially as intelligent, immersive virtual systems (e.g., virtual reality, augmented reality, mixed reality, extended reality) become ubiquitous, offering new opportunities for researchers and educators to explore key areas of metacognition outside of the traditional methodology affordances.

Researchers also continue to consider the role of conscious versus automatic metacognitive processes. For example, does metacognition, by definition, require conscious processing, or can metacognitive activities also appear on a less conscious level? How can researchers capture automatic metacognitive processes? How does drawing attention to one's own automatic metacognitive processes impact their cognition and metacognition? This issue needs to be addressed by advancing new measurement methods and techniques where multiple approaches (e.g., self-reports, concurrent and retrospective verbalizations) may need to be combined in order to capture metacognitive processes during learning, problem solving, task performance, and even their transfer to other topics, domains, and contexts. For example, if through repeated practice, metacognitive processes became automatic and then learners are faced with an atypical, or non-isomorphic, complex transfer task, would they revert to more effortful processing and therefore reveal conscious metacognitive processes? Or contrarily, would they reveal otherwise hidden misconceptions or errors in their metacognition? Additionally, what is the time-based (in the scale of minutes, days, months, years) transition between conscious and automatic activities, and are the changes based on individual differences (e.g., expertise level), familiarity with the task, learning context, goal of the task (e.g., an expert whose automated metacognitive processes used in their domain reverts to consciously and overtly modeling these same metacognitive processes when teaching a novice how to monitor one's understanding during problem solving)?

Another persistent issue is distinguishing between domain-generality versus domain-specificity of metacognition. It is argued that general metacognition may be instructed concurrently in different learning situations and thus expected to transfer to new learning situations, whereas specific metacognition must be taught for each task or domain separately (Veenman et al. 2006). This is a major issue that deserves priority given national and international focus on twenty-first Century skills, automation in the workforce, and the need for learners and workers to be flexible, adaptive, and capable of transferring metacognitive knowledge and skills to a variety of evolving challenges (e.g., remote learning during pandemics, automation in the workplace) and in real-world applications (Greene et al. 2015; Kleitman and Narciss 2019). Aside from the developmental trajectory in acquiring metacognitive knowledge and skills, the question remains of how to best teach and train learners to develop both domain-general and domain-specific metacognition. This challenge extends, not only to learners and workers, but also to teacher preparation programs where teaching teachers to learn, use, model, instruct, and foster metacognition in their students is paramount for enhancing teacher preparation for future learning (Callan and Shim 2019; Dignath and Buttner 2018; Kramarski 2018). A related issue that deserves increased research is the fostering metacognitive training for teachers themselves (i.e., how can they teach it without understanding it themselves).

This issue raises several important questions about the (1) sequencing of training (e.g., declarative followed by procedural and then conditional knowledge and skills?); (2) length of training regiments (e.g., declarative will presumably take less time to master than conditional 
knowledge and skills); (3) tasks to use and embed in the teaching and training regiments (e.g., same tasks within topic or across domains, isomorphic tasks across topics or domains); (4) who or what should deliver the teaching and training (e.g., teacher, parent, peer, expert, or artificial agent such as a virtual human or robot, or a combination of human and artificial agents); (5) instructional model used to guide the training regiments (e.g., modeling by expert while vicarious learning by teacher or learner, then practice using acquired metacognitive knowledge and skills with adaptive scaffolding by expert, and then once mastery shows fade all scaffolding; then repeat cycle for next domain-general and domain-specific metacognitive knowledge and skills); (6) measuring the quantitative and qualitative metacognitive knowledge and skills (e.g., use advanced learning technology such as immersive virtual learning environments to detect, track, model, and prompt while using data visualizations to illustrate the multi-faced nature of domain-general vs. domain-specific metacognition) with problems from the same domain and other domains, and (7) developing new transfer tasks and assessments capable of detecting learners acquiring, internalizing, retaining, retrieving, using, and transferring their metacognitive knowledge and skills competently.

The previous issue is intimately tied to the conditions for acquiring and instructing metacognition. While most learners acquire metacognitive knowledge and skills at a varying level of proficiency from their parents, peers, and teachers, they still show considerable varying metacognitive adequacy (Dunlosky and Lipko 2007). The literature on metacognitive instruction clearly indicates that three conditions for acquiring and instructing metacognition must include (1) embedding metacognitive instruction in the content matter to ensure connectivity, (2) informing learners about the usefulness of metacognitive activities to make them exert the initial extra effort, and (3) prolonging training to guarantee the smooth and maintained application of metacognitive activity. Despite these global principles, there are a few notable examples in math (Kramarski and Michalsky 2013), writing (Hacker 2018; Harris and Graham 2017) and reading (Griffin et al. 2019), but the instruction of metacognition remains largely unexplored. Lastly, many of the issues presented above related to distinction between domain-generality versus domain-specificity of metacognition apply to this issue as well.

The developmental processes in metacognition remain an important area in the field led mostly by developmental psychologists. Despite the clear picture emerging from the literature on metacognition development (e.g., Hoyle and Dent 2018; Schneider and Löffler 2016) involving the development of Theory-of-Mind somewhere between the age of 3 to 5 years, followed by the development of metamemory and metacognitive knowledge and skills that continue to develop throughout the lifespan there is still much to be explored (Roebers and Spiess 2017). Also, it seems that metacognitive skills initially develop in separate domains, and later become generalized across domains (Veenman and Spaans 2005). However, future research needs to determine the processes that are responsible for this transfer across domains along the developmental trajectory. These processes raise issues related to transfer, connection between instruction and feedback provided by teachers, parents, and peers, and the development of these processes in formal and informal educational and workplace settings. The ubiquitous accessibility to different types of learning technologies (e.g., serious games, simulations, immersive virtual systems) raises the question as to whether the development of metacognition can be accelerated based on technology use in our society. Similarly, how does more ubiquitous technological accessibility impact the structure and development of metacognition?

Over the last decade major advances have been made in assessing metacognition. While self-report questionnaires, interviews, and observations are still widely used by researchers, 
there has been a recent surge in research using process-oriented methods such as combining concurrent think-louds, log files, eye tracking, screen recordings of learner-system interactions and so forth (Azevedo et al. 2019; Järvelä and Bannert 2020; Lajoie et al. 2020). These obtrusive and unobtrusive methods have been used extensively in laboratory studies but are slowly transitioning to real-world settings such as classrooms, homes, informal settings (e.g., museums, summer camps, after school programs), workplaces, and embedded in advanced learning technologies (e.g., instrumented participant using an intelligent tutoring system to learn about human body systems; Taub and Azevedo 2019), etc., where metacognitive processes can now be detected, measured, tracked, and modeled with more precision and accuracy. Despite the strengths of these new techniques and methods, researchers continue to grapple with issues of validity, reliability, missing data, instrument error, inferences about specific metacognitive processes based on multimodal data channels, temporally aligning data, mapping metacognitive processes to theoretically-based assumptions, etc. (Azevedo and Gasevic 2019; Graesser 2020; Hadwin 2020; Reimann 2020; Winne 2019). In addition to resolving these challenges, work also needs to be augmented by using multi-method designs that converge multiple sources of metacognitive data with studies that last longer than a few minutes, hours, or days (i.e., longitudinal studies would be ideal but are not always practical and are expensive to carry out). Lastly, the recent emergence in using data mining and machine learning to study metacognition (Biswas et al. 2018) has contributed immensely to understanding the nature of metacognitive processes, especially with advanced learning technologies.

There is a need to continue examining the relations between metacognition and individual differences. While there is abundant research on prior knowledge, metacognitive experiences, epistemological beliefs, metacognitive knowledge, and self-regulation, there is a need for more research on the role of motivational processes (e.g., self-efficacy and regulatory skills), emotional processes (e.g., emotion regulation skills), personality traits, working memory capacity, etc. Individual differences need to be considered when measuring, understanding, and predicting metacognition across learners of all ages as well as domains and tasks, and how this interacts with contextual variables.

Lastly, neuropsychological research on metacognition continues to be limited and focuses on very specific metacognitive processes (e.g., Rahnev and Fleming 2019). The field would benefit tremendously by increasing this kind of research extended to other components of metacognition and SRL such as planning, reflection, and so forth. Understanding the neural substrates of metacognition based on the localization and activation related to metacognitive functioning could significantly enhance our understanding of learners developing metacognition, augmenting the explanatory adequacy of a unified theory of metacognition, potentially having instructional and clinical benefits as well as providing real-time neural data to that can be used both by humans (e.g., learners, teachers, trainers) and machines to modify, enhance, or augment learning and performance through the use of sophisticated devices such as braincomputer interfaces.

In conclusion, the field of metacognition has and continues to make significant strides. There are many conceptual, theoretical, methodological, and analytical issues that still need to be addressed for the field to grow and be impactful. This is an exciting time as so many researchers across various disciplines focus on studying metacognition, but as exciting as that is, we must remain cautious to not repeat the above-mentioned issues so we can advance the field. We are living in an exhilarating time where, for example, using advanced learning technologies (e.g., virtual reality, augmented reality, extended reality, collaborative games, 
tangible computing) as they become increasingly more sophisticated and intelligent research and learning tools, are becoming capable of addressing most of the issues raised in this editorial.

Here is a brief scenario into the future of metacognition research using advanced learning technologies both as a research and learning tool. Imagine a collaborative intelligent virtual reality system with multiple intelligent virtual humans modeled after a new unified theory of metacognition. Each intelligent virtual human embodies the assumptions of the theory and can model several domain-general and domain-specific metacognitive processes. While the system provides the learner with complex and challenging STEM problems, each intelligent virtual human is capable of providing developmentally-appropriate metacognitive scaffolding based on each learner's individual differences, and metacognitive developmental competencies. While they can each automatically detect and intelligently model temporally unfolding metacognitive processes (as well as other processes such as cognitive reappraisal), they can also consciously instruct and teach metacognitive knowledge and skills to learners using a multitude of approaches (e.g., modeling metacognitive conditional knowledge). Since the system is used throughout semester- or year-long interactions, the intelligent virtual humans can self-modify their own cognitive architectures based on their understanding of learners' metacognition and their own metacognition. The methodological tools component of the VR system and its vast amount of trace and other data collected over time and across learners and problems can be used to address definitional, conceptual, theoretical, methodological, and instructional issues in the field. Given the importance of metacognition the field will continue to flourish as metacognition researchers adopt contemporary and emerging interdisciplinary methods, techniques, and tools to significantly advance the field.

Acknowledgements The author would like to thank Elizabeth Cloude, Daryn Dever, Megan Wiedbusch, and Michelle Taub for comments on a previous version of this manuscript. The author would also like to thank the staff at Springer for their continued support of the journal.

Funding information This manuscript was supported by funding from the National Science Foundation (DRL\#1661202, DUE\#1761178, DRL\#1916417, and IIS\#1917728), Institute of Education Sciences (R305A170441), Social Sciences and Humanities Research Council of Canada (SSHRC 895-2011-1006), and the University of Central Florida (IR2). Any opinions, findings, conclusions, or recommendations expressed in this material are those of the author and do not necessarily reflect the views of the National Science Foundation, Social Sciences and Humanities Research Council of Canada, Institute of Education Sciences or the University of Central Florida.

\section{References}

Ackerman, R., \& Thompson, V. (2017). Meta-reasoning: Monitoring and control of thinking and reasoning. Trends in Cognitive Sciences, 21, 607-617.

Azevedo, R., \& Gasevic, D. (2019). Analyzing multimodal multichannel data about self-regulated learning with advanced learning technologies: issues and challenges. Computers in Human Behavior, 96, 207-210.

Azevedo, R., Mudrick, N. V., Taub, M., \& Bradbury, A. (2019). Self-regulation in computer-assisted learning systems. In J. Dunlosky \& K. Rawson (Eds.), Handbook of cognition and education (pp. 587-618). Cambridge: Cambridge University Press.

Biswas, G., Baker, R., \& Paquette, L. (2018). Data mining methods for assessing self-regulated learning. In D. H. Schunk \& J. A. Greene (Eds.), Handbook of self-regulation of learning and performance (2nd ed., pp. 388404). New York: Routledge.

Callan, G., \& Shim, S. (2019). How teachers define and identify self-regulated learning. The Teacher Educator, $54,295-312$. 
Dignath, C., \& Buttner, G. (2018). Teachers' direct and indirect promotion of self-regulated learning in primary and secondary school mathematics classes - Insights from video-based classroom observations and teacher interviews. Metacognition and Learning, 13, 127-157.

Dunlosky, J., \& Lipko, A. (2007). Metacomprehension: a brief history and how to improve its accuracy. Current Directions in Psychological Science, 16, 228-232.

Dunlosky, J., \& Rawson, K. (2019). (Eds.). The Cambridge handbook of cognition and education. Cambridge, MA: Cambridge University Press.

Efklides, A., Schwartz, B., \& Brown, V. (2018). Motivation and affect in self-regulated learning: Does metacognition play a role? In D. Schunk \& J. A. Greene (Eds.), Handbook of self-regulation of learning and performance (2nd ed., pp. 64-82). New York: Routledge.

Graesser, A. C. (2020). Learning science principles and technologies with agents that promote deep learning. In R. S. Feldman (Ed.), Learning science: Theory, research, and practice (pp. 2-33). New York: McGrawHill.

Greene, J. A., Bolick, C. M., Jackson, W. P., Caprino, A. M., Oswald, C., \& McVea, M. (2015). Domainspecificity of self-regulated learning processing in science and history digital libraries. Contemporary Educational Psychology, 42, 111-128.

Griffin, T. D., Mielicki, M. K., \& Wiley, J. (2019). Improving students' metacomprehension accuracy. In J. Dunlosky, K. Rawson, \& K. (Eds.), The Cambridge handbook of cognition and education (pp. 619-646). Cambridge: Cambridge University Press.

Hacker, D. (2018). A metacognitive model of writing: an updated from a development perspective. Educational Psychologist, 53, 220-237.

Hacker, D., \& Bol, L. (2019). Calibration and self-regulated learning: Making the connections. In J. Dunlosky \& K. Rawson (Eds.), The Cambridge handbook of cognition and education (pp. 647-677). Cambridge: Cambridge University Press.

Hadwin, A. (2020). Commentary and future directions: what can multimodal data reveal about temporal and adaptive processes in self-regulated learning? Learning and Instruction.

Hadwin, A. F., Järvelä, S., \& Miller, M. (2017). Self-regulation, co-regulation, and shared regulation in collaborative learning environments. In D. H. Schunk \& J. A. Greene (Eds.), Handbook of self-regulation of learning and performance (2nd ed., pp. 83-106). New York: Routledge.

Harris, K. R., \& Graham, S. (2017). Self-regulated strategy development: theoretical bases, critical instructional elements, and future research. In R. Fidalgo, K. R. Harris, \& M. Braaksma (Eds.), Design principles for teaching effective writing: Theoretical and empirical grounded principles (pp. 119-151). Leiden: Brill.

Hoyle, R., \& Dent, A. (2018). Developmental trajectories of skills and abilities relevant for self-regulated learning and performance. In D. Schunk \& J. A. Greene (Eds.), Handbook of self-regulation of learning and performance (2nd ed., pp. 49-63). New York: Routledge.

Järvelä, S., \& Bannert, M. (2020). Temporal and adaptive processes of regulated learning-What can multimodal data tell? Learning and Instruction.

Kleitman, S., \& Narciss, S. (2019). Introduction to the special issue "applied metacognition: real-world applications beyond learning”. Metacognition and Learning, 14, 335-342.

Koriat, A. (2015). Metacognition: decision-making processes in self-monitoring and self-regulation. In G. Keren \& G. Wu (Eds.), The Wiley Blackwell handbook of judgment and decision making (Vol. 1, pp. 356-379). Malden: Wiley-Blackwell.

Kralik, J., Lee , J., Rosenbloom, P., Jackson, P., Epstein, S., Romero, O., Sanz , R., Larue, O., Schmidtke, H., Lee, S., \& McGreggor, K. (2020). Metacognition for a common model of cognition. Procedia of Computer Science.

Kramarski, B. (2018). Teachers as agents in prompting students' SRL and performance: applications for teachers' dual role training programs. In D. Schunk \& J. A. Greene (Eds.), Handbook of self-regulation of learning and performance (2nd ed., pp. 223-240). New York: Routledge.

Kramarski, B., \& Michalsky, T. (2013). Student and teacher perspectives on IMPROVE self-regulation prompts in web-based learning. In R. Azevedo \& V. Aleven (Eds.), International handbook of metacognition and learning technologies (pp. 35-51). Amsterdam: Springer.

Lajoie, S. P., Azevedo, R., Pekrun, R., \& Leighton, J. (2020). Understanding and measuring emotions in technology-rich learning environments. Learning and Instruction.

Linnenbrink-Garcia, L., Patall, E., \& Pekrun, R. (2016). Adaptive motivation and emotion in education: research and principles for instructional design. Policy Insights From the Behavioral and Brain Sciences, 3, $228-236$.

Metcalfe, J. (2009). Metacognitive judgments and control of study. Current Directions in Psychological Science, $18,159-163$.

Nelson, T., \& Narens, L. (1990). Metamemory: a theoretical framework and new findings. The psychology of learning and motivation (pp. 125-173). New York: Academic press. 
Norman, E., Pfuhl, G., Saele, R., Svartdal, F., Låg, T., \& Dahl, T. (2019). Metacognition in psychology. Review of General Psychology, 23, 403-424.

Panadero, E. (2017). A review of self-regulated learning: six models and four directions for research. Frontiers in Psychology, 8, 1-28.

Rahnev, D., \& Fleming, S. M. (2019). How experimental procedures influence estimates of metacognitive ability. Neuroscience of Consciousness, 5, 1-9.

Reimann, P. (2020). Methodological progress in the study of self-regulated learning enables theory advancement. Learning and Instruction.

Renninger, K. A., \& Hidi, S. (2019). The Cambridge handbook of motivation and learning. Cambridge: Cambridge University Press.

Roebers, C., \& Spiess, M. (2017). The development of metacognitive monitoring and control in second graders: a short-term longitudinal study. Journal of Cognition and Development, 18, 110-128.

Schneider, W., \& Löffler, E. (2016). The development of metacognitive knowledge in children and adolescents. In J. Dunlosky \& S. K. Tauber (Eds.), The Oxford handbook of metamemory (pp. 491-518). Oxford: Oxford University Press.

Schunk, D., \& Greene, J. (2018). Handbook of self-regulation of learning and performance (2nd ed.). New York: Routledge.

Tarricone, P. (2011). A taxonomy of metacognition. New York: Academic Press.

Taub, M., \& Azevedo, R. (2019). How does prior knowledge influence fixations on and sequences of cognitive and metacognitive SRL processes during learning with an ITS? International Journal of Artificial Intelligence in Education, 29, 1-28.

Veenman, M. V. J., \& Spaans, M. A. (2005). Relation between intellectual and metacognitive skills: Age and task differences. Learning and Individual Differences, 15, 159-176.

Veenman, M. V. J., Van Hout-Wolters, B., \& Afflerbach, P. (2006). Metacognition and learning: Conceptual and methodological considerations. Metacognition and Learning, 1, 3-14.

Winne, P. H. (2018). Cognition and metacognition within self-regulated learning. In D. Schunk \& J. A. Greene (Eds.), Handbook of self-regulation of learning and performance (2nd ed., pp. 254-270). New York: Routledge.

Winne, P. H. (2019). Paradigmatic dimensions of instrumentation and analytic methods in research on selfregulated learning. Computers in Human Behavior, 96, 285-289.

Publisher's note Springer Nature remains neutral with regard to jurisdictional claims in published maps and institutional affiliations. 